\title{
Carotid Disease and Retinal Optical Coherence Tomography Angiography Parameters in Patients with Non-arteritic Anterior İschemic Optic Neuropathy
}

Fatma Selin KAYA ( $\square$ fatselink@gmail.com )

Çam and Sakura City Hospital

\section{Research Article}

Keywords: Nonarteritic anterior ischemic optic neuropathy, optical coherence tomography angiography, carotid artery stenosis, peripapillary capillary density

Posted Date: March 2nd, 2021

DOl: https://doi.org/10.21203/rs.3.rs-255139/v1

License: (c) (i) This work is licensed under a Creative Commons Attribution 4.0 International License. Read Full License

Version of Record: A version of this preprint was published at International Ophthalmology on August 18th, 2021. See the published version at https://doi.org/10.1007/s10792-021-02007-5. 


\section{Abstract}

Purpose: To analyze the data and retinal microvasculature for nonarteritic anterior ischemic optic neuropathy (NAION) patients referred to have carotid Doppler ultrasound from 2016 to 2020.

Methods: In this case-control observational study, 30 NAION patients evaulated with carotid doppler sonography. 22 NAION patients (at least 3 months after onset of symptoms) and 9 normal subjects underwent a complete ophthalmic examination including optical coherence tomography (OCT), optical coherence tomography angiography (OCT-A). NAION eyes and fellow eyes were further divided into the groups according to presence of carotid stenosis (CS). NAION patients with CS were termed "CS-NAION"; those without were termed "NCSNAION". Measurements of radial peripapillary capillary vessel density (RPC VD) and ganglion cell complex (GCC), disk retinal nerve fiber layer (RNFL) thickness were compared among groups.

Results: Fourteen of 30 NAION patients referred for carotid Doppler were positive for CS with all of such referrals having less than $50 \%$ stenosis. RNLF, GCC and RPC VDs were reduced in NAION eyes, when compared to controls and the fellow eyes. RPC VD was significantly lower in the temporal-superior $(P=0.037)$ and the superior-temporal $(P=0.012)$ sectors of the NCS-NAION patients than in the CS-NAION patients. No significant differences were found between CS-fellow eyes and NCS-fellow eyes in terms of RPC VDs, RNLF or GCC.

Conclusion: Results of the study highlight the effect of carotid artery stenosis on ocular perfusion pressure in the pathogenesis of NAION. More extensive studies are necessary.

\section{İntroduction}

Acute optic nerve injury due to nonarteritic anterior ischemic optic neuropathy (NAION) typically causes reduced visual acuity (VA) and significant retinal structural alterations, which almost always is permanent. In recent years imaging methods, such as optical coherence tomography has been used extensively to document swelling and injury at thevarious retinal layers [1, 2, 3]. Given the claimed ischemic pathophysiology, flourescein angiography (FA) and optic coherens angiography (OCT-A) imaging techniques have explored the blood flow or the vasculature in the region of the optic nerve head $(\mathrm{ONH})$, peripapillary retina and choroid. Fluorescein and indocyanine green angiographic studies of the optic disc in NAION showed complete or sectorial delay or absence of filling of the prelaminar optic disc without impairment of the choroidal circulation [4, 5]. However, FA is not sufficiently sensitive to measure the detailed changes of capillaries. OCT-A is a non-invasive technique that provides analysis of the microvasculature of the peripapillary region. Previous studies have reported that swelling of the ONH in NAION causes significant changes in the peripapillary vasculature both at the acute and the atrophic stage $[6,7,8,9,10]$. As previously described, OCT-A findings show very good matching with retinal nerve fiber layer (RNFL) and visual field damages, confirmed by correlation analyses $[8,10]$.

The risk factors for the development of the NAION are hypertension, arteriosclerosis, diabetes, cardiovascular disease, and internal carotid artery occlusion [11, 12]. Color-flow Doppler is a new development of duplex sonography of the peripheral vessels. In a retrospective study with duplex sonography, authors evaulated 191 ophthalmological patients with amaurosis fugax, occluded retinal veins and glaucoma, and found that ophthalmological patients suffered more often from carotid artery stenosis (CS) than asymptomatic people [13].

Given that carotid artery disease can contribute to development of NAION either by embolism or by lowering the perfusion pressure [12], the aim of this study is to evaulate the effect of CS on the capillary density within the optic 
disc and within the peripapillary region in NAION and the fellow eyes.

\section{Methods}

This observational cross-sectional study was conducted in Bakırköy Dr. Sadi Konuk Education and Research Hospital (İstanbul, Turkey). Patients with NAION were recruited from neurophthalmology clinic.

The research protocols were approved by the institutional review board and adhered to the tenets of the Declaration of Helsinki.

Written informed consent was obtained from all volunteers prior to their participation in this study.

Diagnostic criteria for NAION were a sudden onset of painless vision loss; sectorial or generalized optic disc edema, peripapillary hemorrhage and normal erythrocyte sedimentation rate or C-reactive protein. All of the patients underwent ophthalmic evaluation, including best-corrected visual acuity (BCVA) and refraction assessments, slitlamp biomicroscopy, intraocular pressure measurement, $\mathrm{ONH}$ evaluation, fundus examination and digital color fundus photography (Digital Non-Mydriatic Retinal Camera; Topcon), carotid colour doppler sonography. Representative cases of NAION are shown in Fig. 1.Twentytwo patients were retrospectively identified from an internally maintained OCT-A imaging database (at least 3 months of the initial evaulaton). OCT-A images of fellow, unaffected eyes were also evaluated in the study. NAION patients were categorized as either NAION with CS "CSNAION" or NAION without CS "NCS-NAION" based on the presence or absence of CS, at the carotid colour doppler sonography.

The control group comprised age-matched subjects with a BCVA $\geq 0,8, I O P \leq 21 \mathrm{~mm} \mathrm{Hg}$, an open angle, normal optic disc appearance on fundus examination, and no RNFL defects.

Exclusion criteria were as follows: 1 ) refractive error greater than +3.0 diopters (D) or less than -4.0 D; 2 ) previous intraocular surgery other than cataract; 3 ) any other ophthalmic disorder, including corneal opacity, vitreous opacity, diabetic retinopathy, and diseases affecting the optic disc (glaucoma, optic neuritis, uveitis, retinal or choroidal diseases, and trauma); and 4) neurologic diseases that may affect the optic nerve such as multiple sclerosis, Alzheimer disease, and Parkinson disease 5) poor cooperation in OCT imaging studies.

OCT-A was performed with the spectral domain system RTVue-XR Avanti (Optovue Inc. Fremont, California, USA). The peripapillary RNFL was determined using the $\mathrm{ONH}$ protocol. A standard $360^{\circ}, 3.4-\mathrm{mm}$-diameter circular scan was utilized to measure the RNFL thickness, and superior, nasal, temporal and inferior RNFL values were recorded. The macula cube scanning protocol measured the ganglion cell complex (GCC) thickness over a $7 \mathrm{~mm}$ diameter centered on the fovea, inferior, superior and total GCC values were recorded.

The flow density map software AngioAnalytics (RTVue XR version 2018.0.0.18) was automatically employ to quantify vessel density in this study. The OCT-A images were acquired within the peripapillary area (Fig. 2). The retinal peripapillary capillaries (RPC) mode, which included the signals from internal limiting membrane to the nerve fiber layer was employed in this study. In the optic disc scan, the software automatically fits an ellipse to the optic disc margin and calculates the average vessel density within the $\mathrm{ONH}$ and peripapillary area. The peripapillary area is defined as a $0.75 \mathrm{~mm}$-wide elliptical annulus that extends from the optic disc boundary. The peripapillary region is divided into sectors, and the vessel densities in each sector are calculated (nasalinferior, nasalsuperior, inferonasal, inferotemporal, superotemporal, superonasal, temporalinferior and temporalsuperior sectors). For each scanned region, the software automatically calculates the vessel densities. The vessel density (VD) was defined as the percentage of the area occupied by vessels within the segmented area. The signal strength index was employed 
to control for image quality. Images with a signal strength index less than 7 were excluded, and scans with movement or decentration artifacts were repeated.

\section{Results}

This study was designed to analyse data for NAION patients referred to have carotid Doppler ultrasound from 2016 to 2020. Thirty NAION patients evaulated with carotid doppler sonography in the present study. There were 14 patients with CS in the NAION group. Eight patients had contralateral CS, 5 patients bilateral CS and 1 patient had ipsilateral CS. The degree of stenosis was below the $50 \%$ in all patients.

Twenty two of the 30 NAION patients and 9 controls were analyzed with OCTA in the study. Nine of the 22 NAION patients ( 6 men and 3 women, age $60.3 \pm 8.7$ years) had CS, there was no CS in 13 NAION patients ( 6 men and 7 women, age $55.0 \pm 8.5$ years). Patients were aged $59.82 \pm 8.2$ years ( 5 men and 4 women) in control group. Two patients with CS and 3 patients without CS had bilateral NAION. The mean BCVA (decimal) was $0.55 \pm 0,30$ in the CS-NAION patients, $0,45 \pm 0.36$ in the NCS -NAION patients and 1 in the control subjects. Of the 22 patients with NAION, 10 eyes from 9 NAION patients with CS and 16 eyes from 13 NAION patients without CS were imaged in the atrophic phase. Seventeen unaffected (fellow) eyes were also analyzed by OCT-A using the same quantitative method for comparison between the eyes with CS (n:7) and without CS (n:10). All 7 fellow eyes of CS-NAION patients had ipsilateral CS.

The mean GCC thickness, RNLF thickness parameters were comparable between the CS-NAION, NCS-NAION patients and significantly lower in both of the groups than in the healthy controls. The quantitative results are presented in Table 1. 
Table 1

Demographics, Ganglion Cell Complex Thickness, Peripapillary Retinal Nerve Fiber Layer Thickness and Vessel Density in Healthy eyes, NAION eyes with Carotid Artery Stenosis and NAION eyes without Carotid Artery Stenosis: Univariate and Multivariate Analysis

\begin{tabular}{|c|c|c|c|c|c|c|c|c|c|c|c|c|c|}
\hline \multirow[b]{3}{*}{ Age } & \multicolumn{3}{|l|}{ A } & \multicolumn{3}{|l|}{ B } & \multicolumn{3}{|l|}{ C } & \multirow{3}{*}{$\begin{array}{l}P \\
\text { value } \\
0,483\end{array}$} & \multirow{3}{*}{$\begin{array}{l}\mathrm{P}^{A C} \\
0,699\end{array}$} & \multirow{3}{*}{$\begin{array}{l}P^{B C} \\
0,470\end{array}$} & \multirow{3}{*}{$\begin{array}{l}\mathrm{P}^{\mathrm{AB}} \\
0,200\end{array}$} \\
\hline & \multicolumn{3}{|c|}{ Mean \pm sd } & \multicolumn{3}{|c|}{ Mean \pm sd } & \multicolumn{3}{|c|}{ Mean \pm sd } & & & & \\
\hline & 60,3 & \pm & 8,7 & 55,0 & \pm & 8,5 & 59,1 & \pm & 8,2 & & & & \\
\hline Visual Acuity & 0,55 & \pm & 0,30 & 0,45 & \pm & 0,36 & 1,00 & \pm & 0,00 & 0,000 & 0,000 & 0,000 & 0,558 \\
\hline GCC-Avarage & 77,9 & \pm & 14,1 & 69,9 & \pm & 9,9 & 95,9 & \pm & 5,1 & 0,000 & 0,003 & 0,000 & 0,215 \\
\hline GCC-Superior & 72,4 & \pm & 15,4 & 66,6 & \pm & 9,9 & 95,6 & \pm & 6,1 & 0,000 & 0,000 & 0,000 & 0,235 \\
\hline GCC-İnferioır & 83,5 & \pm & 20,0 & 73,4 & \pm & 14,5 & 96,6 & \pm & 4,9 & 0,001 & 0,048 & 0,000 & 0,205 \\
\hline RNFL-Superior & 81,2 & \pm & 25,5 & 59,9 & \pm & 24,2 & 120,4 & \pm & 12,2 & 0,000 & 0,000 & 0,000 & 0,052 \\
\hline RNFL-Nasal & 76,3 & \pm & 37,5 & 68,8 & \pm & 18,9 & 96,3 & \pm & 10,3 & 0,000 & 0,039 & 0,000 & 0,833 \\
\hline RNFL-Inferior & 90,3 & \pm & 30,0 & 90,8 & \pm & 46,5 & 130,7 & \pm & 12,0 & 0,001 & 0,002 & 0,003 & 0,598 \\
\hline $\begin{array}{l}\text { RNFL- } \\
\text { Temporal }\end{array}$ & 54,7 & \pm & 16,7 & 53,1 & \pm & 14,0 & 70,9 & \pm & 11,7 & 0,000 & 0,008 & 0,000 & 0,895 \\
\hline $\begin{array}{l}\text { C/D Volume } \\
\text { Ratio }\end{array}$ & 0,04 & \pm & 0,14 & 0,19 & \pm & 0,26 & 0,26 & \pm & 0,29 & 0,072 & 0,053 & 0,306 & 0,105 \\
\hline $\begin{array}{l}\text { C/D Area } \\
\text { Ratio }\end{array}$ & 0,02 & \pm & 0,06 & 0,08 & \pm & 0,12 & 0,14 & \pm & 0,18 & 0,069 & 0,052 & 0,262 & 0,121 \\
\hline Disc Area & 2,03 & \pm & 0,28 & 2,17 & \pm & 0,47 & 1,99 & \pm & 0,43 & 0,522 & 0,669 & 0,377 & 0,280 \\
\hline Whole & 40,2 & \pm & 4,1 & 36,6 & \pm & 6,5 & 47,7 & \pm & 1,6 & 0,000 & 0,000 & 0,000 & 0,146 \\
\hline Inside & 47,8 & \pm & 4,0 & 43,6 & \pm & 7,0 & 46,9 & \pm & 4,5 & 0,088 & 0,649 & 0,080 & 0,050 \\
\hline Peripapillary & 40,4 & \pm & 6,4 & 35,2 & \pm & 6,9 & 49,9 & \pm & 2,6 & 0,000 & 0,000 & 0,000 & 0,091 \\
\hline Superior-Hemi & 38,5 & \pm & 7,1 & 32,9 & \pm & 6,4 & 50,0 & \pm & 2,3 & 0,000 & 0,000 & 0,000 & 0,081 \\
\hline
\end{tabular}

Kruskal Wallis / Mann-Whitney U test

Values are presented as the mean \pm standard deviation.

Systatistically significant values are shown in bold.

A: NAION Eyes with Carotid Artery Stenosis

B: NAION Eyes without Carotid Artery Stenosis

C: Healthy Controls

$\mathrm{P}^{\mathrm{AC}}$ :Difference with Control eyes \& NAION Eyes with Carotid Artery Stenosis

$\mathrm{P}^{\mathrm{BC}}$ :Difference with Control eyes \& NAION Eyes without Carotid Artery Stenosissis

$\mathrm{P}^{\mathrm{AB}}$ : NAION Eyes without Carotis Stenosis \& NAION Eyes withCarotid Artery Stenosis 


\begin{tabular}{|c|c|c|c|c|c|c|c|c|c|c|c|c|c|}
\hline \multirow{3}{*}{ Inferior-Hemi } & \multirow{2}{*}{\multicolumn{3}{|c|}{$\begin{array}{l}\text { A } \\
\text { Mean } \pm \text { sd }\end{array}$}} & \multirow{2}{*}{\multicolumn{3}{|c|}{$\begin{array}{l}\text { B } \\
\text { Mean } \pm \text { sd }\end{array}$}} & \multirow{2}{*}{\multicolumn{3}{|c|}{$\begin{array}{l}\text { C } \\
\text { Mean } \pm s d\end{array}$}} & \multirow{3}{*}{$\begin{array}{l}\text { P } \\
\text { value } \\
0,000\end{array}$} & \multirow{3}{*}{$\begin{array}{l}P^{A C} \\
0,004\end{array}$} & \multirow{3}{*}{$\begin{array}{l}P^{B C} \\
0,000\end{array}$} & \multirow{3}{*}{$\begin{array}{l}P^{A B} \\
0,170\end{array}$} \\
\hline & & & & & & & & & & & & & \\
\hline & 42,4 & \pm & 7,2 & 37,6 & \pm & 8,6 & 52,6 & \pm & 13,1 & & & & \\
\hline Nasal-Superior & 33,3 & \pm & 13,9 & 33,9 & \pm & 8,6 & 47,2 & \pm & 4,2 & 0,000 & 0,002 & 0,000 & 0,912 \\
\hline Nasal-Inferior & 38,9 & \pm & 8,6 & 35,8 & \pm & 9,2 & 45,8 & \pm & 3,2 & 0,002 & 0,036 & 0,000 & 0,359 \\
\hline Inferior-Nasal & 42,8 & \pm & 13,0 & 33,9 & \pm & 10,0 & 47,8 & \pm & 6,8 & 0,004 & 0,378 & 0,000 & 0,169 \\
\hline $\begin{array}{l}\text { Inferior- } \\
\text { Temporal }\end{array}$ & 47,9 & \pm & 13,2 & 39,5 & \pm & 14,8 & 54,5 & \pm & 3,9 & 0,033 & 0,392 & 0,012 & 0,113 \\
\hline $\begin{array}{l}\text { Temporal- } \\
\text { Inferior }\end{array}$ & 40,2 & \pm & 10,5 & 40,7 & \pm & 10,3 & 50,9 & \pm & 4,7 & 0,006 & 0,014 & 0,004 & 0,874 \\
\hline $\begin{array}{l}\text { Temporal- } \\
\text { Superior }\end{array}$ & 43,4 & \pm & 7,3 & 36,9 & \pm & 8,4 & 53,5 & \pm & 5,5 & 0,000 & 0,002 & 0,000 & 0,037 \\
\hline $\begin{array}{l}\text { Superior- } \\
\text { Temporal }\end{array}$ & 40,1 & \pm & 10,0 & 29,4 & \pm & 8,4 & 54,4 & \pm & 2,6 & 0,000 & 0,000 & 0,000 & 0,012 \\
\hline Superior-Nasal & 34,6 & \pm & 10,4 & 29,2 & \pm & 8,4 & 46,9 & \pm & 4,2 & 0,000 & 0,003 & 0,000 & 0,119 \\
\hline \multicolumn{14}{|c|}{ Kruskal Wallis / Mann-Whitney U test } \\
\hline \multicolumn{14}{|c|}{ Values are presented as the mean \pm standard deviation. } \\
\hline \multicolumn{14}{|c|}{ Systatistically significant values are shown in bold. } \\
\hline \multicolumn{14}{|c|}{ A: NAION Eyes with Carotid Artery Stenosis } \\
\hline \multicolumn{14}{|c|}{ B: NAION Eyes without Carotid Artery Stenosis } \\
\hline \multicolumn{14}{|c|}{ C: Healthy Controls } \\
\hline \multicolumn{14}{|c|}{$\mathrm{P}^{\mathrm{AC}}$ :Difference with Control eyes \& NAION Eyes with Carotid Artery Stenosis } \\
\hline \multicolumn{14}{|c|}{$\mathrm{P}^{\mathrm{BC}}$ :Difference with Control eyes \& NAION Eyes without Carotid Artery Stenosissis } \\
\hline
\end{tabular}

Table 1 shows the RPC VD results for the peripapillary area in CS-NAION, NCS-NAION and control groups. The RPC VDs were significantly lower in all the sectors of the peripapillary area in both of the groups than in the healthy controls. This density was significantly lower in the temporal-superior $(P=0.037)$ and the superior-temporal $(P=$ 0.012) sectors of the NCS-NAION patients than in the CS-NAION patients.

The RPC VD results for the fellow eyes of the NAION patients are shown in Table 2. All of the measurements were comparable between the groups except for the visual acuity $(P=0.001$ for both) (Table 2$)$. 
Table 2

Demographics, Ganglion Cell Complex Thickness, Peripapillary Retinal Nerve Fiber Layer Thickness and Vessel Density in Healthy eyes, Fellow eyes with Carotid Artery Stenosis and Fellow eyes without Carotid Artery Stenosis: Univariate and Multivariate Analysis

\begin{tabular}{|c|c|c|c|c|c|c|c|c|c|c|c|c|c|}
\hline \multirow{3}{*}{ Age } & \multirow{2}{*}{\multicolumn{3}{|c|}{$\begin{array}{l}\text { D } \\
\text { Mean } \pm \text { sd }\end{array}$}} & \multirow{2}{*}{\multicolumn{3}{|c|}{$\begin{array}{l}\text { E } \\
\text { Mean } \pm \text { sd }\end{array}$}} & \multirow{2}{*}{\multicolumn{3}{|c|}{$\begin{array}{l}F \\
\text { Mean } \pm \text { sd }\end{array}$}} & \multirow{3}{*}{$\begin{array}{l}\mathbf{P} \\
\text { value } \\
0,423\end{array}$} & \multirow{3}{*}{$\begin{array}{l}P^{D F} \\
0,423\end{array}$} & \multirow{3}{*}{$\begin{array}{l}P^{E F} \\
0,768\end{array}$} & \multirow{3}{*}{$\begin{array}{l}P^{D E} \\
0,410\end{array}$} \\
\hline & & & & & & & & & & & & & \\
\hline & \multirow{2}{*}{$\begin{array}{l}63,8 \\
0,86\end{array}$} & \multirow{2}{*}{$\begin{array}{l} \pm \\
\pm\end{array}$} & 12,0 & \multirow{2}{*}{$\begin{array}{l}56,2 \\
0,92\end{array}$} & \pm & 12,8 & \multirow{2}{*}{$\begin{array}{l}59,1 \\
1,00\end{array}$} & \pm & 8,2 & & & & \\
\hline $\begin{array}{l}\text { Visual } \\
\text { Acuity }\end{array}$ & & & 0,16 & & \pm & 0,18 & & \pm & 0,00 & 0,001 & 0,001 & 0,040 & 0,230 \\
\hline $\begin{array}{l}\text { GCC- } \\
\text { Avarage }\end{array}$ & 93,1 & \pm & 22,2 & 94,7 & \pm & 13,6 & 95,9 & \pm & 5,1 & 0,339 & 0,339 & 0,763 & 0,845 \\
\hline $\begin{array}{l}\text { GCC- } \\
\text { Superior }\end{array}$ & 91,9 & \pm & 22,6 & 93,1 & \pm & 15,9 & 95,6 & \pm & 6,1 & 0,408 & 0,408 & 0,633 & 1,000 \\
\hline $\begin{array}{l}\text { GCC- } \\
\text { İnferioır }\end{array}$ & 94,3 & \pm & 22,4 & 96,6 & \pm & 12,0 & 96,6 & \pm & 4,9 & 0,426 & 0,426 & 0,960 & 0,845 \\
\hline $\begin{array}{l}\text { RNFL- } \\
\text { Superior }\end{array}$ & 103,0 & \pm & 44,9 & 121,0 & \pm & 28,4 & 120,4 & \pm & 12,2 & 0,726 & 0,726 & 0,406 & 0,328 \\
\hline RNFL-Nasal & 89,0 & \pm & 41,2 & 103,0 & \pm & 31,5 & 96,3 & \pm & 10,3 & 0,357 & 0,357 & 0,940 & 0,435 \\
\hline $\begin{array}{l}\text { RNFL- } \\
\text { Inferior }\end{array}$ & 102,7 & \pm & 34,3 & 129,1 & \pm & 28,7 & 130,7 & \pm & 12,0 & 0,052 & 0,052 & 0,841 & 0,130 \\
\hline $\begin{array}{l}\text { RNFL- } \\
\text { Temporal }\end{array}$ & 65,1 & \pm & 22,0 & 73,5 & \pm & 17,9 & 70,9 & \pm & 11,7 & 0,726 & 0,726 & 0,598 & 0,464 \\
\hline $\begin{array}{l}\text { C/D Volume } \\
\text { Ratio }\end{array}$ & 0,07 & \pm & 0,19 & 0,08 & \pm & 0,16 & 0,26 & \pm & 0,29 & 0,082 & 0,082 & 0,080 & 0,883 \\
\hline $\begin{array}{l}\text { C/D Area } \\
\text { Ratio }\end{array}$ & 0,03 & \pm & 0,08 & 0,02 & \pm & 0,05 & 0,14 & \pm & 0,18 & 0,082 & 0,082 & 0,080 & 0,883 \\
\hline Disc Area & 1,96 & \pm & 0,32 & 2,04 & \pm & 0,44 & 1,99 & \pm & 0,43 & 0,924 & 0,924 & 0,581 & 0,625 \\
\hline Whole & 46,3 & \pm & 9,3 & 47,3 & \pm & 3,3 & 47,7 & \pm & 1,6 & 0,386 & 0,386 & 0,819 & 0,556 \\
\hline Kruskal Walli & / Mann- & & ey U te & & & & & & & & & & \\
\hline Values are pr & ented a & & hean \pm & tandar & & ation. & & & & & & & \\
\hline Systatisticall & significa & & ues ar & shown & & & & & & & & & \\
\hline D: Fellow Eye & of NAIO & & eints $n$ & th Carot & & ery Ste & osis & & & & & & \\
\hline E: Fellow Eye & of NAIO & & eints $w$ & thout $\mathrm{Ca}$ & & Artery & tenosis & & & & & & \\
\hline F: Healthy Co & trols & & & & & & & & & & & & \\
\hline $\mathrm{P}^{\mathrm{DF}}:$ Differen & with $\mathrm{Cc}$ & & yes \& & ellow E & & NAION & Pateint & & Caroti & Artery $S$ & enosis & & \\
\hline $\mathrm{P}^{\mathrm{EF}}$ :Differen & with $\mathrm{Cc}$ & & yes \& & ellow E & & NAION & Pateint & & ut $\mathrm{Ca}$ & tid Arte & Steno & & \\
\hline $\begin{array}{l}\mathrm{P}^{\mathrm{ED}} \text { : Fellow E } \\
\text { Carotid Artery }\end{array}$ & $\begin{array}{l}\text { S of NA } \\
\text { tenosis }\end{array}$ & & teints & ith $\mathrm{Ca}$ & & tery $s$ & nosis 8 & & vyes & f NAIO & Patein & vithou & \\
\hline
\end{tabular}




\begin{tabular}{|c|c|c|c|c|c|c|c|c|c|c|c|c|c|}
\hline & D & & & E & & & $F$ & & & $\mathbf{P}$ & $\mathrm{P}^{\mathrm{DF}}$ & PEF & PDE \\
\hline & Mean & & & Mean & & & Mean & & & & & & \\
\hline Inside & 49,6 & \pm & 4,8 & 49,9 & \pm & 5,2 & 46,9 & \pm & 4,5 & 0,126 & 0,126 & 0,137 & 0,845 \\
\hline Peripapillary & 47,4 & \pm & 11,4 & 49,6 & \pm & 3,7 & 49,9 & \pm & 2,6 & 0,544 & 0,544 & 0,839 & 0,731 \\
\hline $\begin{array}{l}\text { Superior- } \\
\text { Hemi }\end{array}$ & 45,7 & \pm & 13,9 & 49,4 & \pm & 4,1 & 50,0 & \pm & 2,3 & 0,501 & 0,501 & 0,704 & 0,806 \\
\hline $\begin{array}{l}\text { Inferior- } \\
\text { Hemi }\end{array}$ & 48,7 & \pm & 9,1 & 49,5 & \pm & 3,3 & 52,6 & \pm & 13,1 & 0,924 & 0,924 & 0,723 & 0,659 \\
\hline $\begin{array}{l}\text { Nasal- } \\
\text { Superior }\end{array}$ & 43,7 & \pm & 12,6 & 47,3 & \pm & 5,1 & 47,2 & \pm & 4,2 & 0,798 & 0,798 & 0,980 & 0,922 \\
\hline $\begin{array}{l}\text { Nasal- } \\
\text { Inferior }\end{array}$ & 44,3 & \pm & 9,8 & 44,2 & \pm & 4,9 & 45,8 & \pm & 3,2 & 0,949 & 0,949 & 0,349 & 0,659 \\
\hline $\begin{array}{l}\text { Inferior- } \\
\text { Nasal }\end{array}$ & 48,9 & \pm & 10,3 & 50,2 & \pm & 5,7 & 47,8 & \pm & 6,8 & 0,656 & 0,656 & 0,327 & 1,000 \\
\hline $\begin{array}{l}\text { Inferior- } \\
\text { Temporal }\end{array}$ & 55,4 & \pm & 8,0 & 55,7 & \pm & 2,3 & 54,5 & \pm & 3,9 & 0,503 & 0,503 & 0,507 & 0,588 \\
\hline $\begin{array}{l}\text { Temporal- } \\
\text { Inferior }\end{array}$ & 47,6 & \pm & 10,1 & 50,0 & \pm & 4,7 & 50,9 & \pm & 4,7 & 0,482 & 0,482 & 0,464 & 0,769 \\
\hline $\begin{array}{l}\text { Temporal- } \\
\text { Superior }\end{array}$ & 48,4 & \pm & 14,7 & 50,2 & \pm & 5,2 & 53,5 & \pm & 5,5 & 0,924 & 0,924 & 0,113 & 0,405 \\
\hline $\begin{array}{l}\text { Superior- } \\
\text { Temporal }\end{array}$ & 48,6 & \pm & 16,3 & 51,9 & \pm & 7,6 & 54,4 & \pm & 2,6 & 0,369 & 0,369 & 0,578 & 0,769 \\
\hline $\begin{array}{l}\text { Superior- } \\
\text { Nasal }\end{array}$ & 43,4 & \pm & 14,1 & 47,4 & \pm & 5,4 & 46,9 & \pm & 4,2 & 0,874 & 0,874 & 0,840 & 0,961 \\
\hline Kruskal Wallis & / Manr & Vhit & ey U te & & & & & & & & & & \\
\hline Values are pre & ented & & nean \pm & standa & & ation & & & & & & & \\
\hline Systatistically & signific & it va & ues ar & shown & bo & & & & & & & & \\
\hline D: Fellow Eyes & of $\mathrm{NAi}$ & $\mathrm{Pa}$ & eints $n$ & th Carc & $\mathrm{Ar}$ & ery $\mathrm{S}$ & osis & & & & & & \\
\hline E: Fellow Eyes & of NAil & $\mathrm{Pa}$ & eints $w$ & thout C & otic & Arter & tenosis & & & & & & \\
\hline F: Healthy Cor & rols & & & & & & & & & & & & \\
\hline$P^{D F}:$ Differenc & with C & trol & eyes \& & Eellow & & NAiC & Patein & & Caroti & Artery $\varsigma$ & enosis & & \\
\hline$P^{E F}$ :Difference & with $\mathrm{C}$ & & eyes \& & ellow & & $\mathrm{Ani}$ & Patein & & 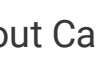 & tid Arte & Stenos & & \\
\hline
\end{tabular}

Fellow eyes and NAION eyes of both categories of patients showed similar disc area and cup to disc ratio, cup to disc volume ratio parameters as in healthy controls. The quantitative results are presented in Table 1 and Table 2. 


\section{Discussion}

$\mathrm{n}$ this retrospective study, 14 of the 30 NAION patients had carotid artery stenosis. There was also systatistically significant difference in RPC layer between the subgroups of NAION patients in the superior temporal sectors.

The optic disc blood flow in NAION was previously investigated using various methods. Using a laser Doppler flowmeter, Leiba et al. demonstrated that the ONH blood flow in NAION eyes is significantly lower than that in healthy control eyes [14]. Decrease in peripapillary retinal perfusion has also been reported in NAION eyes by using Doppler OCT[15]. OCT-A is currently the preferred method for mapping ocular perfusion, including capillaries. Recently, several studies on ocular microvasculature in NAION have been reported. Some studies have examined NAION eyes with swollen dics using OCT-A, and reported dilation of patent superficial capillaries in the peripapillary area (16) and reduction of the peripapillary vascular density associated with the acute phase of NAION $(6,7)$. Some other studies have also assessed microvascular changes in atrophic NAION eyes using OCT-A [8, 9, 10]. Liuet al. studied 13 eyes of 13 NAION patients and reported the quantitative OCT-A results for non- acute NAION eyes [9]. Similar to the peresent study; they found a reduced vascular density in peripapillary area. Two quantitative studies, also using Optovue devices, reported microvascular attenuation in the non-acute phase of NAION with correlation between areas of vascular attenuation and RNFL atrophy or visual field loss $[8,10]$. The authors proposed that the decreased RNFL and GCC owing to NAION, results in decreased metabolic activities and blood flow via autoregulatory mechanisms $[8,10,17]$. Results of the current study are in line with the above studies. In the present study, eyes of the NAION patients were analyzed in subgroups according to presence of CS and contralateral unaffected eyes were included, in order to analyze eventual possible differences with respect to healthy controls. This study confirmed the statistically significant vascular impairment occurring in NAION eyes. Fellow eyes of both categories of patients showed normal vascular network smilar to healthy controls. In the present study, there was a difference between vessel density parameters in the sub-group analysis. Vessel density showed significant reductions in superior temporal region in NCS-NAION compared to CS-NAION patients. Previosly Yu et al reported significantly smaller diameter RPCs in the temporal region [18]. Accordingly, it can be speculated that due to the capillaries with smaller diameter the hemodynamic instabilities might effect temporal sectors selectively.

NAION is presumed to be caused by acute hemodynamic insufficiency in optic nerve circulation, 915resulting in $\mathrm{ONH}$ infarction. The pathogenesis of acute NAION is believed to be multifactorial, including the acute hypoperfusion of short posterior ciliary arteries $[12,19,20]$ There has been no thrombosis demonstrated in the short posterior ciliary arteries in the histopathological studies performed in NAION eyes [21, 22]. Internal carotid artery supply blood to the eye, therefore stenosis of internal carotid artery caused by artheriosclerosis may effect the visual functioning. A video fluorescein angiography study on 33 patients with carotid artery stenosis by Wolf et al. reported decreased retinal perfusion in all patients and prolonged arterio-venous passage time in 18 of them[23]. İn the current study all fellow eyes of the patients had ipsilateral CS in the CS-NAION group. However, fellow and normal eyes showed no significant difference in vessel density at the paripapillary region among the groups. These results indicate that the capillary vasculature may not be affected in CS. It is worth noting that the degree of obstruction was below the $\% 50$ percent in all eyes.

Zhu et al demonstrated that presence of carotid artery plaque was more frequent in the patients with NAION, compared to either the hypertensive group or the normal controls, indicating NAION may be associated with carotid artery atherosclerosis [24]. Their suggestion is in line with our conclusion. Although they found that the CS was more often in NAION patients the mechanism is unclear. One possible explanation might be the disruption of vazomotor autoregulation. Mense et al demonstrated that patients with carotid stenosis had impaired baroreceptor

Page $9 / 13$ 
reflex and reduced cerebral autoregulation which could lead to hemodynamic insufficiency [25]. It is not known why the sensitivity of baroreceptors in the carotid sinus is impaired in patients with carotid stenosis. Previously Kitagawa proposed that thickness and rigidity of carotid atheromatous plaque could impede the transmission of intraluminal pressure to the adventitia where baroreceptors exist [26]. Given that the CS was at the contralateral side in most of the NAION patients this result was unexpected. Based on on the findings of the current study, it can be suggested that the CS might activate the compensatory mechanisms to avoid the reduction of the ocular blood flow on the ipsilateral side in chronic situations. These mechanisms might be protective against the serious perfusion reduction which might be responsible also of an irreversible vascular damage. However, this hypothesis requires further studies to prove.

The study had several limitations. One of the main drawbacks was the small study population. Future research is needed to confirm our findings and also to determine the results in larger groups. This was a cross sectional study with a single observation at one specific point. Further investigation needs to be carried out to clarify the long-term effect of CS on ocular vasculature.

\section{Declarations}

\section{Funding:}

No funding was received to assist with the preparation of this manuscript.

The author has no relevant financial or non-financial interests to disclose.

This study was performed in line with the principles of the Declaration of Helsinki. Approval was granted by the Ethics Committee of İstanbul Bakırköy Dr. Sadi Konuk Research and Education Hospital (Date 2020/No 12).

\section{References}

1. Gonul S, Koktekir BE, Bakbak B et al (2013) Comparison of the ganglion cell complex and retinal nerve fibre layer measurements using Fourier domain optical coherence tomography to detect ganglion cell loss in nonarteritic anterior ischaemic optic neuropathy. Br J Ophthalmol 97(8):1045-1050

2. Aggarwal D, Tan O, Huang D et al (2012) Patterns of ganglion cell complex and nerve fiber layer loss in nonarteritic ischemic optic neuropathy by Fourier-domain optical coherence tomography. Invest Ophthalmol Vis Sci 53(8):4539-4545

3. Goto K, Miki A, Araki S et al (2016) Time Course of Macular and Peripapillary Inner Retinal Thickness in Nonarteritic Anterior Ischaemic Optic Neuropathy Using Spectral-Domain Optical Coherence Tomography. Neuroophthalmology 40(2):74-85

4. Oto S, Yilmaz G, Cakmakci S,et al (2002) Indocyanine green and fluorescein angiography in nonarteritic anterior ischemic optic neuropathy. Retina 22:187-191

5. Arnold AC, Hepler RS (1994) Fluorescein angiography in acute nonarteritic anterior ischemic optic neuropathy. Am J Ophthalmol 117:222-230

6. Rougier MB, Delyfer MN, Korobelnik JF (2017) OCT angiography of acute non-arteritic anterior ischemic optic neuropathy. J Fr Ophtalmol 40:102-109 
7. Sharma S, Ang M, Najjar RP, Sng C, Cheung CY et al (2017) Optical coherence tomography angiography in acute non-arteritic anterior ischaemic optic neuropathy. Br J Ophthalmol 101:1045-1051

8. Wright Mayes E, Cole ED, Dang S et al (2017) Optical Coherence Tomography Angiography in Nonarteritic Anterior Ischemic Optic Neuropathy. J Neuroophthalmol Dec;37(4):358-364

9. Liu CH, Wu WC, Sun MH,et al (2017) Comparison of the Retinal Microvascular Density Between Open Angle Glaucoma and Nonarteritic Anterior Ischemic Optic Neuropathy. Invest Ophthalmol Vis Sci Jul 1(9):3350-3356 58(

10. Hata M, Oishi A, Muraoka Y,et al (2017) Structural and Functional Analyses in Nonarteritic Anterior Ischemic Optic Neuropathy: Optical Coherence Tomography Angiography Study. J Neuroophthalmol Jun 37(2):140-148

11. Burde RM (1993) Optic disk risk factors for nonarteritic anterior ischemic optic neuropathy. Am J Ophthalmol 116:759-764

12. Hayreh SS (2000) Ischaemic optic neuropathy. Indian J Ophthalmol Sep 48(3):171-194

13. Metzler W, Kessler G, Benzer W et al (1990) Ophthalmologische Bedeutung stenosierender Karotisprozesse [Ophthalmological significance of stenosing carotid processes]. Wien Med Wochenschr Jul 31(14):387-389 140(

14. Leiba H, Rachmiel R, Harris A et al (2000) Optic nerve head blood flow measurements in non-arteritic anterior ischaemic optic neuropathy. Eye 14(Pt 6):828-833

15. Wang Y, Fawzi AA, Varma R et al (2011) Pilot study of optical coherence tomography measurement of retinal blood flow in retinal and optic nerve diseases. Invest Ophthalmol Vis Sci 52:840-845

16. Gaier ED, Wang M, Gilbert AL et al (2018) Quantitative analysis of optical coherence tomographic angiography (OCT-A) in patients with non-arteritic anterior ischemic optic neuropathy (NAION) corresponds to visual function. PLoS One 13(6):e0199793

17. Higashiyama T, Ichiyama Y, Muraki S et al.(2016)Optical Coherence Tomography Angiography in a Patient with Optic Atrophy After Non-arteritic Anterior Ischaemic Optic Neuropathy. Neuroophthalmology. 40(3):146-149

18. Yu PK, Cringle SJ, Yu DY (2014) Correlation between the radial peripapillary capillaries and the retinal nerve fibre layer in the normal human retina. Exp Eye Res 129:83-92

19. Hayreh SS, Zimmerman MB, Podhajsky P et al (1994) Nocturnal arterial hypotension and its role in optic nerve head and ocular ischemic disorders. Am J Ophthalmol 117:603-624

20. Arnold AC (2003) Pathogenesis of nonarteritic anterior ischemic optic neuropathy. J Neuroophthalmol 23:157163

21. Knox DL, Duke JR (1971) Slowly progressive ischemic optic neuropathy. A clinicopathologic case report. Trans Am Acad Ophthalmol Otolaryngol 75(5):1065-1068

22. Levin LA, Louhab A (1996) Apoptosis of retinal ganglion cells in anterior ischemic optic neuropathy. Arch Ophthalmol 114(4):488-491

23. Wolf S, Rebstock J, Bertram B et al (1989) Retinal hemodynamics and morphologic findings in patients with occlusion of the internal carotid artery] Fortschritte der Ophthalmologie: Zeitschrift der Deutschen Ophthalmologischen Gesellschaft. 86(4):339-342

24. Zhu W, Chen T, Jin L et al (2017) Carotid artery intimal medial thickness and carotid artery plaques in hypertensive patients with non-arteritic anterior ischaemic optic neuropathy. Graefes Arch Clin Exp Ophthalmol 255(10):2037-2043 
25. Mense L, Reimann M, Rüdiger $\mathrm{H}$ et al (2010) Autonomic function and cerebral autoregulation in patients undergoing carotid endarterectomy. Circt „J 74:2139-2145

26. Kitagawa K (2010) Carotid stenosis, baroreceptor sensitivity and cerebral autoregulation - implication for cerebral hyperperfusion syndrome. Circ J 74(10):2058-2059

\section{Figures}

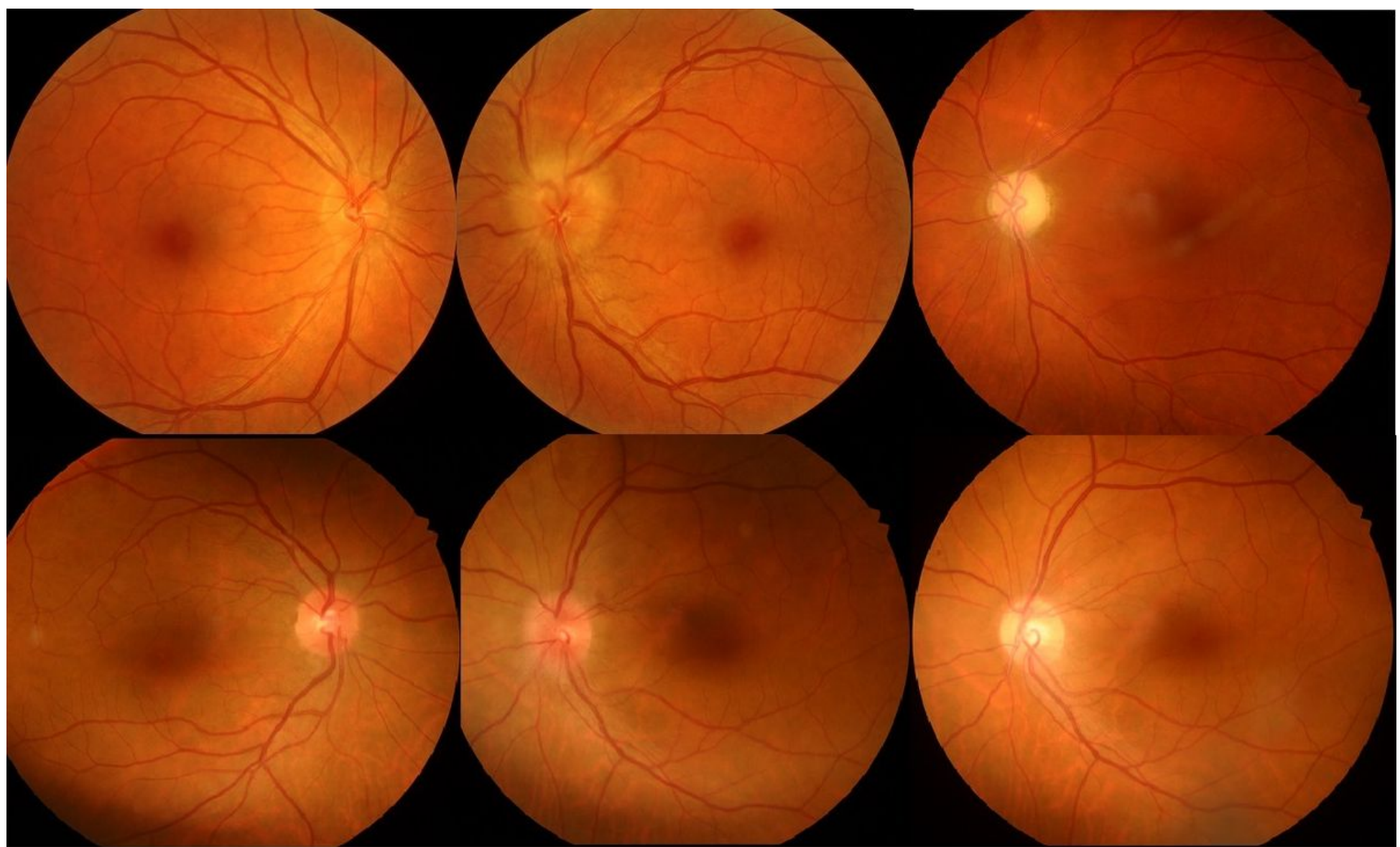

\section{Figure 1}

First row: Color fundus photography of NAION patient without carotid stenosis, fellow eye and the NAION eye in the atrophic stage. Second row: Color fundus photography of NAION patient with carotid stenosis, fellow eye and the NAION eye in the atrophic stage. 


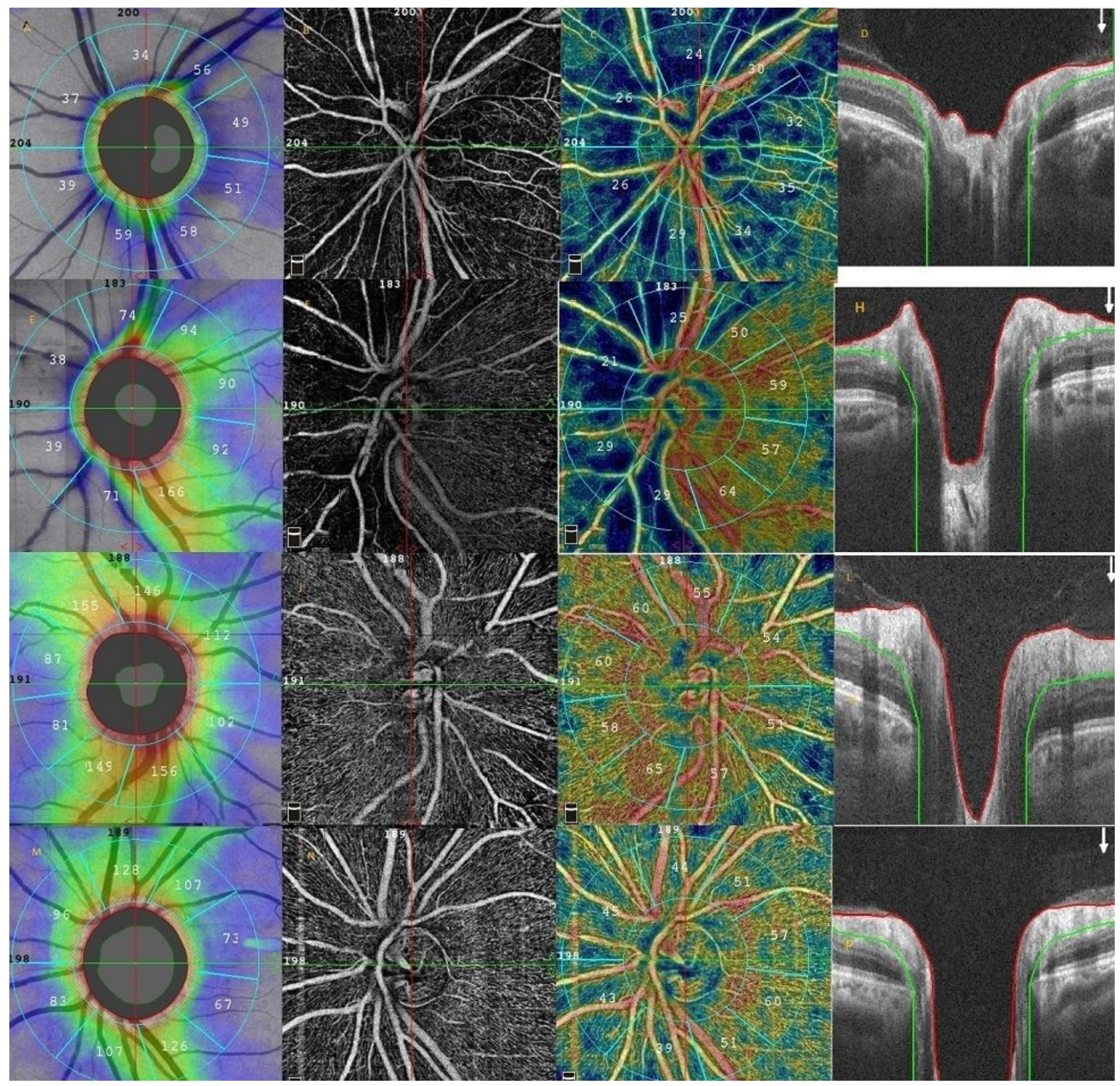

Figure 2

Oct- A images of the subjects; first row: NAION patient without carotid stenosis, second row: NAION patient with carotid stenosis, third row: fellow eye of NAION patient with carotid stenosis, Last row: healthy control. First two cases showed a damage of retinal nerve fiber layer (RNLF) $(A, E)$ which was more extensive in the NAiON patient without carotid stenosis (A). Diffuse $(A)$ and sectorial vasculer perfusion defect (E)in en face optical coherence tomography angiograms (OCT-A) in the radial peripapillary capillary (RPC) layer consistent with the blue areas on color vascular density map. OCT-angiography reveals a normal vascular network in the fellow eye of the NAION patient with carotid stenosis $(\mathrm{J}, \mathrm{K})$ and healthy control $(\mathrm{N}, \mathrm{O})$. Last coloumn, B-scan image of the segmentation of the optic nerve head radial peripapillary capillary plexus of the subjects. 